\title{
Ocular knowledge and practice among type 2 diabetic patients in a tertiary care hospital in Bangladesh
}

\author{
Kazi Rumana Ahmed ${ }^{1,2^{*}}$, Fatema Jebunessa ${ }^{3}$, Sharmin Hossain ${ }^{1}$ and Hasina Akhter Chowdhury ${ }^{4}$
}

\begin{abstract}
Background and aims: Diabetes mellitus is likely to have a major effect on vision, and adequate knowledge of its ocular manifestations is of substantial importance to diabetic patients. The study aimed to assess the ocular knowledge and practices among Type 2 diabetic patients of Bangladesh.

Methods: This cross-sectional study included 122 diabetic patients from the outpatient department (OPD) of the apex diabetic healthcare hospital of the country under the sponsorship of the Diabetic Association of Bangladesh (BIRDEM). A questionnaire was used for collecting data on knowledge on and practices relating to diabetes mellitus with particular emphasis on ocular issues. A predefined score was used for categorizing levels of knowledge and practices as poor, average, and good.
\end{abstract}

Results: Of the 122 respondents, 63\%, 55\%, 40\%, 44\%, and 30\% reported, blindness, retinopathy, cataracts, glaucoma, and double vision respectively, as complications of diabetes mellitus. About $50 \%$ were aware of the need for eye screening for people with the complications. Only $8 \%$ monitored their blood glucose levels daily, 15\% monitored weekly, and $10 \%$ reported checking their blood pressure daily and $43 \%$ took their medications as prescribed. The level of diabetic knowledge was poor, moderate and good, respectively, among 24\%, 56\%, and 20\% of the respondents, whereas the practice standards showed that 47\%,31\%, and 22\% had poor, average, and good levels respectively. The knowledge score was significantly associated with the practice score $(r=0.460, p=0.001)$.

Conclusion: The results indicate that the ocular knowledge and practices among diabetic patients attending a tertiary-care hospital in Bangladesh is average. Health and eye-care practitioners need to expand diabetic health education and promotion among diabetic patients.

Keywords: Type 2 diabetes, Ocular knowledge, Practice, Hospital-based study, Bangladesh

\section{Background}

Diabetes mellitus (DM) is a growing global epidemic and leading cause of ocular complications, eye complications, and eye diseases, such as cataract, retinopathy, glaucoma, double vision, macular degeneration, and blindness [1]. The longer duration of DM is associated with ocular complications, resulting in visual impairment and blindness.

\footnotetext{
* Correspondence: lopa_birdem@yahoo.com

${ }^{1}$ Department of Health Promotion and Health Education, Bangladesh University of Health Sciences, 125/1, Darus Salam, Mirpur-1, Dhaka, Bangladesh

${ }^{2}$ School of Health and Rehabilitation Sciences, The University of Queensland, Brisbane, Australia

Full list of author information is available at the end of the article
}

The rising trend of non-communicable diseases, especially DM, along with lifestyle-related factors, such as diet, sedentary lifestyle, and smoking [2, 3], are the likely causes of reversible vision loss in Bangladesh. Results of studies in Bangladesh among persons, aged $\geq 30$ years, showed that $22.6 \%$ were suffering from low vision [4], and $22.1 \%$ were myopia [5].

Kknowledge on the prevention and risk factors of ocular complications is essential to prevent vision loss among DM patients. Although the majority of diabetes patients are aware that diabetes can cause eye diseases, their attitude and practice is not at the desired level, which need to be improved [6]. The need for greater awareness of prevention, diagnosis, control of risk 
factors and disease management is well-documented in various studies. [7, 8]. Results of a population-based study on eye diseases in a rural district in Bangladesh showed that $58 \%$ of participants did not have any idea about their vision loss, which could be prevented [3]. Results of a community-based study among diabetic patients showed that males were more likely than females to know that diabetes causes eye diseases (18\% vs $13 \%)$, and $38 \%$ of patients with at least SSC level of education knew that diabetes causes eye diseases compared to those with no schooling (9\%) $p=0.001$ [9]. Although the respondents could define diabetes, they had poor knowledge on ocular complications and also had poor attitude and practice relating eye care.

To the best of our knowledge, no hospital-based study was conducted in Bangladesh to understand the knowledge and practices of diabetic patients relating to eye diseases. The presents study was therefore undertaken to assess the level of ocular-related knowledge and practices among type 2 diabetic patients in a tertiary-care hospital in Bangladesh.

\section{Methods}

Using a cross-sectional study design, 122 adult diabetic patients were included from the outpatient department of the Bangladesh Institute of Research \& Rehabilitation in Diabetes, Endocrine and Metabolic Disorders (BIRDEM), which is an apex diabetic healthcare hospital of the country under the sponsorship of the Diabetic Association of Bangladesh [10]. Detailed profiles of diabetic patients were obtained from the patient's guidebook in the hospital. Furthermore, an ophthalmologist confirmed eye complications due to diabetes.

\section{Study population}

All the registered diabetic patients who visited the ophthalmic OPD during were conserved for inclusion in the study. A pilot study was conducted in the ophthalmic OPD among 18 diabetic patients who did not take part in the final study. All the queries arising from the pilot study were addressed before the final study was conducted.

\section{Sample-size}

In this study, the prevalence of knowledge on eye disorders among DM patients was considered $75.62 \%$ [6] for determining the sample-size using the following formula: $\mathrm{n}=\mathrm{z} 2 \mathrm{q} / \mathrm{r} 2 \mathrm{p}$. Thus, the sample-size was approximately 125 .

\section{Sampling technique}

Systematic sampling method was followed to select subjects for the study. Every 10th DM patient from each ophthalmologist patient's registry book was selected to participate in the study till the sample-size of the study had achieved.

\section{Questionnaire}

Most (97.5\%) of the participants answered the questionnaire voluntarily, and confidentiality was maintained throughout the study. A face-to-face interview was conducted by trained interviewers using a twopart semi-structured questionnaire. The first part of the questionnaire contained socio-demographic information (i.e. age, gender, socioeconomic status, education) of the patients, duration of DM, and complications due to diabetes. The second part contained 11 questions, of which seven questions were about knowledge of patients on ocular complications due to DM and four were related to ocular self-care practices of the patients. Knowledge was defined as the understanding of information regarding ocular knowledge, and practice was defined as the understanding of information regarding ocular practice relating to diabetes.

\section{KAP scoring}

The maximum attainable scores for knowledge and practices were 7 and 4 in that order, and the minimum score was ' 0 '. The levels of (poor, average, and good) knowledge and the practice scores were considered as (mean $\pm 1 \mathrm{SD}$ ) [11]. The levels of knowledge and practices were categorized based on each respondent's attainable score.

\section{Statistical analysis}

At the end of interviews, the researchers checked and verified data. Descriptive statistics was used for analyzing the sociodemographic characteristics and knowledge of the respondents on different aspects of ocular complications due to diabetes. Pearson's correlation was performed to determine the association between the knowledge and the practices of the participants. The SPSS software (version 16.0) was used for analyzing all the data.

\section{Ethical aspects}

The ethics review committee of the Bangladesh University of Health Sciences approved the study protocol.

\section{Results}

The mean $( \pm S D)$ age of the 122 participants was $57 \pm 8$ years. Of them, a male $(55 \%)$ preponderance was observed. The majority (62\%) of the respondents had higher secondary education and above. Around 30\% were from a high-income group. Forty-six percent were engaged in different types of activities (Table 1).

The majority (63\%) of the respondents pointed out blindness as an eye complication due to diabetes, followed by diabetic retinopathy (55\%) and other eye complications. Forty-nine percent had concept about the necessity of regular eye screening. In reply to a 
Table 1 Characteristics of the study subjects $(n=122)$

\begin{tabular}{|c|c|}
\hline Variables & n (\%) \\
\hline \multicolumn{2}{|l|}{ Age (yrs) } \\
\hline$\leq 45$ & $10(8.2)$ \\
\hline $46-65$ & $91(74.6)$ \\
\hline$>65$ & $21(17.2)$ \\
\hline Mean $\pm S D$ & $57.57 \pm 8.76$ \\
\hline \multicolumn{2}{|l|}{ Gender } \\
\hline Male & $67(55)$ \\
\hline Female & $55(45)$ \\
\hline \multicolumn{2}{|l|}{ Religion } \\
\hline Muslim & $116(97)$ \\
\hline Hindu & $4(3)$ \\
\hline \multicolumn{2}{|l|}{ Marital Status } \\
\hline Married & $119(98)$ \\
\hline Unmarried & $3(2)$ \\
\hline \multicolumn{2}{|l|}{ level of Education } \\
\hline Primary to Secondary & $47(38)$ \\
\hline Higher Secondary-Graduate \& above & $75(62)$ \\
\hline \multicolumn{2}{|l|}{ Occupation } \\
\hline Unemployed & $66(54)$ \\
\hline Employed & $56(46)$ \\
\hline \multicolumn{2}{|l|}{ Socio-economic status (BDT*) } \\
\hline Low income $(\leq 10,000)$ & $47(38.5)$ \\
\hline Middle income $(10001-20,000)$ & $39(32)$ \\
\hline High income $(>20,000)$ & $36(29.5)$ \\
\hline \multicolumn{2}{|l|}{ Duration of diabetes (yrs) } \\
\hline Mean \pm SD & $9.75 \pm 3.15$ \\
\hline \multicolumn{2}{|l|}{ Diabetes status } \\
\hline Controlled Group & $48(39)$ \\
\hline Uncontrolled Group & $74(61)$ \\
\hline
\end{tabular}

Results are expressed number (percentage) and mean \pm SD;

*BDT $=$ Bangladeshi Taka

question on the frequency of the test, $35 \%$ indicated to perform it in every 6-12 months (Table 2).

On eye-care practices, only $8 \%$ monitored their blood sugar daily; around 10\% checked their blood pressure daily; and $43 \%$ always took medications as prescribed by the physicians. Around $37 \%$ visited an eye specialist once a year to prevent vision loss and other diabetesassociated eye complications (Table 3).

The overall level of knowledge was poor, average, and good, respectively, among $24 \%, 56 \%$, and $20 \%$ of the patients. Regarding practices, the corresponding values were poor in $47 \%$, average in $31 \%$, and good in $22 \%$ of the participants (Fig.1) respectively. On Pearson's correlation, a significant positive association $(r=0.460$,
Table 2 Responses of different questions related to ophthalmic knowledge among patients with diabetes

\begin{tabular}{ll}
\hline Ophthalmic knowledge/Indicator & $\begin{array}{l}\text { Correct Answer } \\
{[\mathrm{n}(\%)]}\end{array}$ \\
\hline $\begin{array}{l}\text { Knowledge of diabetic eye complication* } \\
\text { Blindness }\end{array}$ & $65(63)$ \\
Diabetic retinopathy & $67(55)$ \\
Cataracts & $49(40)$ \\
Glaucoma & $54(44)$ \\
Double vision & $37(30)$ \\
Knowledge of Eye Screening in diabetes mellitus & \\
Yes, to eye screening & $59(49)$ \\
Frequency of Eye screening & \\
Every 6-12 months & $43(35)$
\end{tabular}

Results are expressed as number (\%)

*Multiple Responses

$p=0.001)$ was found between the knowledge and the practice score (Fig.2).

\section{Discussion}

Diabetes mellitus is the most widespread public-health challenge that has been confronting the present century. Its timely management and routine eye examinations can decrease or delay its complications [6]. Our main objective was to investigate the levels of knowledge of the diabetic patients about ocular issues.

Table 3 Summary results of different types of self-care practices with diabetes

Practice related variables $\quad$ Percentage (\%)

Monitor blood glucose

Daily

$10(8)$

Weekly

18 (15)

Monthly

$45(37)$

Never

$49(40)$

Blood pressure monitor

Daily

$12(10)$

Weekly

4 (3)

Monthly

49 (40)

Never

57 (47)

Adherence to medication

Regular

$53(43)$

Irregular

$69(57)$

Visiting an eye specialist

Every 6-12 months 13 (11)

Every year 45 (37)

Felt problem with vision 64 (52)

Results are expressed as number (\%) 


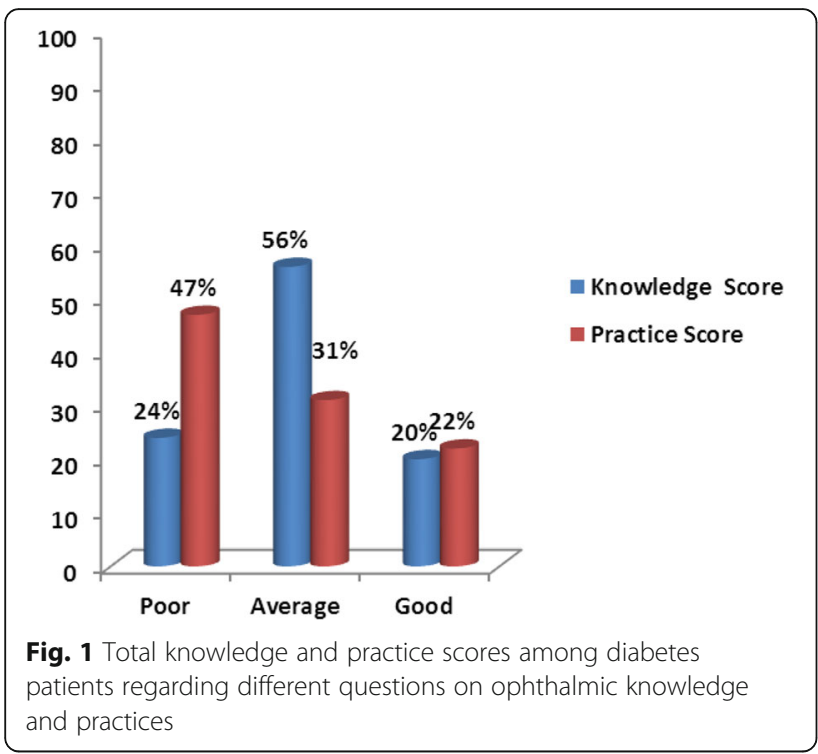

The findings of our study re-assert the gaps between the ophthalmic knowledge and the practices among the diabetic patients in Bangladesh. The period of onset of ophthalmic complications determines the type of diabetes an individual suffers [12]. Approximately 25\% of type 2 diabetic patients develop some degree of diabetic retinopathy before their diagnosis. [13, 14].

This study has shown that $63 \%, 55 \%$, and $40 \%$ of the patients had adequate knowledge, respectively, on the complications of blindness, retinopathy, and cataract associated with DM. Thirty percent had adequate knowledge on the complications of double vision associated with this condition. Results of a similar study in Oman revealed that $72.9 \%$ of diabetic patients had adequate knowledge on ophthalmic complications [15], which is much more than that in our study. Results of other studies showed that over 95\% of subjects were concerned about DM and its ophthalmic consequences [16, 17]. Contrary to our findings was observed in a study conducted in Ghana [12]. Our study focused on insufficient

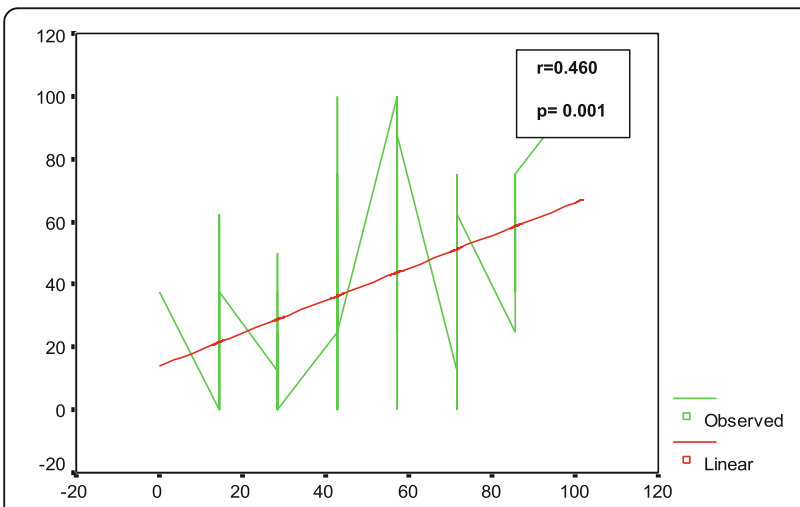

Fig. 2 Association of total knowledge score with total practice score practices (irregular monitoring, non-adherence to lifestyle modification, and medical advices) of the patients relating to regular monitoring of blood glucose and blood pressure, adherence to medications, and visiting an eye specialist. However, in our study, only $37 \%$ of the patients visited the health professionals (physician and ophthalmologist) for regular eye examination annually, and $52 \%$ visited an eye specialist only when they had a vision problem, suggesting that most diabetic patients are not aware that eye complications can be present without any symptom, particularly in the early stages of the condition [18]. This view is supported by the fact that another study reported that only $19.5 \%$ of diabetic patients had their last ocular examinations within a year, and $34.5 \%$ had never any eye examination following the diagnosis of their DM [12]. These results compare well with those reported in Tanzania [19] and South Africa [20]. This finding suggests that lack of knowledge is a major barrier to eye care in Bangladesh. It may be due to the patients said that it is important to have a regular eye examination as per the advice of their physicians. Whether or not this accurately reflects the content of physician-patient discussions in this tertiary-care setting, it clearly indicates that optimal communication of an important piece of diabetic health education does not occur.

Inadequate knowledge on eye care among our patients resulted in the low uptake of eye care compared to participants in the Durban study [20]. However, knowledge of ocular complications and management options were low in our study subjects, which is similar to results obtained in Baltimore, USA [21]. A positive correlation between the knowledge and the practices was noted in this study. The information gap about eye diseases may be attributed to poor knowledge on ocular complications and poor eye-care practices relating to examination of eye complications due to DM. The results of our study also showed that the majority of patients were aware of the need for eye screening but eye-care practices were not at the desired level.

Based on the findings of the present study, it is recommended that the diabetic patients go for at least an annual comprehensive eye examination to facilitate early diagnosis and management of visual disorders associated with this condition to avoid visual impairment and blindness.

\section{Strengths and limitations}

All the diabetic patients in the present study were attending the tertiary-care hospital of BIRDEM for diabetic care. BIRDEM sponsored by the Diabetic Association of Bangladesh and being an apex diabetic healthcare hospital of the country, it receives DM patients from almost all over Bangladesh, including affiliated associations of the 
Diabetic Association of Bangladesh (BADAS). Therefore, data generated from this hospital generally reflect the general diabetic population of the country. However, since the sample was drawn from only one hospital to explore the eye diseases of DM patients, it is a limitation of the study.

\section{Conclusions}

The results of the present study have shown that diabetic patients in this facility had average knowledge but had poor eye-care practice. The results suggest the need for health education for their eye-care practices to reduce ocular complications in diabetic patients.

\section{Abbreviations}

BIRDEM: Bangladesh Institute of Research and Rehabilitation in Diabetes, Endocrine and Metabolic Disorders; DM: Diabetes Mellitus; KAP: Knowledge Attitudes and Practice; OPD: Out Patient Department; SD: Standard Deviation SPSS: Statistical Package for Social Science

\section{Acknowledgements}

We acknowledge the following organization and individuals for their contributions to the research: the study participants, the ophthalmologists, research team members and staffs of the BIRDEM for their kind support. The authors are very grateful to Mr. M Shamsul Islam Khan (Advisor, Department. of Library and Ferdousi Rahman Chair, Department of Applied Language and Culture) of the Bangladesh University of Health Sciences for his professional help for linguistic improvement of this article.

\section{Ethical approval and consent to participate}

Informed written consents were obtained from all the participants after explaining the nature, purpose, and procedures of the study to them, and information relating to the study was treated as confidential. The protocol was approved by the ethics committee of Bangladesh University of Health Sciences (BUHS).

\section{Funding}

This study did not obtain any funding from any source.

\section{Availability of data and materials}

Regarding sharing of the data, the research is still ongoing and is expected to be completed by next year. And the ocular knowledge data are one of the parts of the main dataset of the mentioned research work. At this moment, the authors are unable to share the dataset with others, but will try to share the data in future under a mutual agreement of the concerned authority.

\section{Authors' contributions}

Concept and design (KRA), acquisition of data (KRA, HAC, SH), analysis and interpretation of data (KRA, FJ, HAC, SH), drafting of the manuscript (KRA, SH, $\mathrm{HAC}$ ), drafting of the final article or revising it critically for the important intellectual content (KRA, FJ, SH, HAC), final approval of the version to be submitted (KRA, SH, HAC).

\section{Consent for publication}

Not applicable.

\section{Competing interests}

The authors declare that they have no competing interests.

\section{Publisher's Note}

Springer Nature remains neutral with regard to jurisdictional claims in published maps and institutional affiliations.

\section{Author details}

'Department of Health Promotion and Health Education, Bangladesh University of Health Sciences, 125/1, Darus Salam, Mirpur-1, Dhaka, Bangladesh. ${ }^{2}$ School of Health and Rehabilitation Sciences, The University of
Queensland, Brisbane, Australia. ${ }^{3}$ Department of Biochemistry and Cell Biology, Bangladesh University of Health Sciences, 125/1, Darus Salam, Mirpur-1, Dhaka, Bangladesh. ${ }^{4}$ Department of Biostatistics, Bangladesh University of Health Sciences, 125/1, Darus Salam, Mirpur-1, Dhaka, Bangladesh.

Received: 19 April 2016 Accepted: 29 August 2017

Published online: 19 September 2017

\section{References}

1. Pikayi L, Gladys S, Mukona, Doreen, Zvinavashe, Mathilda. A Pilot Study on Eye Care Knowledge and Practice in Adults with Diabetes Mellitus at Parirenyatwa Central Hospital, Harare, Zimbabwe. Orient J Scientific Res. 2,2. 2013;16:16-21.

2. Alam DS, Jha P, Ramasundarahettige C, Streatfield PK, Niessen LW, Chowdhury MA, et al. Smokingattributable mortality in Bangladesh: proportional mortality. National Blindness and low vision survey of Bangladesh. 2013;91(10):757-64. https://doi.org/10.2471/BLT.13.120196. PMID: 24115799; PubMed Central PMCID: PMC3791659

3. Islam FMA, Chakrabarti R, Islam SZ, Finger RP, Critchley C. Factors associated with awareness, attitudes and practices regarding common eye diseases in the general population in a Rural District in Bangladesh: the Bangladesh population-based diabetes and eye study (BPDES). PLoS One. 2015;10(7): e0133043. https://doi.org/10.1371/journal.pone.013304

4. Dineen BP, Bourne RR, Ali SM, Huq DM, Johnson GJ. Prevalence and causes of blindness and visual impairment in Bangladeshi adults: results of the National Blindness and low vision survey of Bangladesh. Br J Ophthalmol. 2003;87(7):820-8. Epub 2003/06/19. PMID: 12812875; PubMed Central PMCID: PMC1771736

5. Bourne RR, Dineen BP, Ali SM, Noorul Huq DM, Johnson GJ. Prevalence of refractive error in Bangladeshi adults: results of the National Blindness and low vision survey of Bangladesh. Ophthalmology. 2004;111(6):1150-60. https:/doi.org/ 10.1016/j.ophtha.2003.09.046. Epub 2004/06/05 S0161-6420(04)00131-9 [pii]. PMID: 15177965

6. Zarea BKA. Knowledge, attitude and practice of diabetic retinopathy amongst the diabetic patients of AlJouf and Hail Province of Saudi Arabia. Clin Diagn Res. 2016 May;10(5):NC05-8

7. Zaman MJ, Patel A, Jan S, Hillis GS, Raju PK, Neal B, et al. Socio-economic distribution of cardiovascular risk factors and knowledge in rural India International journal of epidemiology. 2012;41(5):1302-14. https://doi.org/10. 1093/ije/dyr226. PMID: 22345313

8. Norris SL, Engelgau MM, Narayan KM. Effectiveness of self-management training in type 2 diabetes: a systematic review of randomized controlled trials. Diabetes Care. 2001;24(3):561-87. Epub 2001/04/ 06. PMID: 11289485

9. Islam FMA, Chakrabarti R, Dirani M, Islam MT, Ormsby G, et al. Knowledge, attitudes and practice of diabetes in rural Bangladesh: the Bangladesh population based diabetes and eye study (BPDES). PLoS One. 2014;9(10): e110368. https://doi.org/10.1371/journal.pone.0110368.

10. DAB. Statistical Year Book. Vol. July 2011-June 2012. Dhaka: Diabetic Association of Bangladesh; 2012.

11. Raj CP, Angadi M. Hospital-based KAP study on diabetes in Bijapur. Karnataka Indian Journal of Medical Specialities. 2011;1(2):80-3.

12. Godwin O, Ovenseri-Ogbomo, Samuel Abokyi, G A Koffuor, and Eric Abokyi. Knowledge of diabetes and its associated ocular manifestations by diabetic patients: A study at Korle-Bu Teaching Hospital, Ghana. Niger Med J. 2013 Jul-Aug; 54(4): 217-223. doi: https://doi.org/10.4103/0300-1652.119602 PMCID: PMC3821220.

13. Cacallerano J. AOA reference guide for clinicians. St Louis: American Optometric Association; 2002. Optometric clinical guidelines. Care of the patient with diabetes mellitus; pp. 13-6.14.

14. Fowler MJ. Microvascular and macrovascular complications of diabetes. Clin Diabetes. 2008;26:77-82

15. Khandekar R, Al Harby S, Al Harthy H, Al LJ. Knowledge, attitude and practice regarding eye complications and care among Omani persons with diabetes - a cross sectional study. Oman J Ophthalmol. 2010;3:60-5.

16. Funatsu H, Hori S, Shimizu E, Nakamura S. Questionnaire survey on periodic ocular examination in Japanese diabetic patients. Am J Ophthalmol. 2003, 136:955-7. [PubMed]

17. Schmid KL, Schmid LM, Pedersen KC. Knowledge of the ocular effects of diabetes among the general population of Australia.

18. Pasagian-Macaulay A, Basch CE, Zybert P, Wylie-Rosett J. Ophthalmic knowledge and beliefs among women with diabetes. The Diabetes Educator. 1997;23:433-7. 
19. Mumba M, Hall A, Lewallen S. Compliance with eye screening examinations among diabetic patients at a Tanzanian referral hospital. Ophthalmic Epidemiol. 2007;14:306-10.

20. Mashige KP, Notshweleka A, Moodley S, Rahmtoola FH, Sayed SB, Singh S, et al. An assessment of the level of diabetic patients' knowledge of diabetes mellitus, its complications and management in Durban. South Africa S Afr Optom. 2008;67:95-105.

21. Muñoz B, O'Leary M, Fonseca-Becker F, Rosario E, Burguess I, Aguilar M, Fickes C, West SK. Knowledge of diabetic eye disease and vision care guidelines among Hispanic individuals in Baltimore with and without diabetes. Arch Ophthalmol. 2008 Jul;126(7):968-74. https://doi.org/10.1001/ archopht.126.7.968.

Submit your next manuscript to BioMed Central and we will help you at every step:

- We accept pre-submission inquiries

- Our selector tool helps you to find the most relevant journal

- We provide round the clock customer support

- Convenient online submission

- Thorough peer review

- Inclusion in PubMed and all major indexing services

- Maximum visibility for your research

Submit your manuscript at www.biomedcentral.com/submit
Biomed Central 